\title{
Conselho Tutelar: mecanismo implementado pelo ECA para 0 atendimento de crianças e adolescentes
}

As políticas sociais têm sido essenciais para que as desigualdades sociais sejam minimizadas no Brasil. O Estatuto da Criança e do Adolescente (ECA), por meio do Conselho Tutelar, contribui significantemente em favor da criança e do adolescente, melhorando a qualidade de vida e seu bem-estar. $O$ presente trabalho tem o objetivo de discutir acerca da criação do ECA, e sobre a atuação e competências do Conselho Tutelar diante das diretrizes regulamentadoras. Trata-se de um estudo bibliográfico exploratório. Este estudo bibliográfico demonstrou as oportunidades geradas em prol da criança por meio das políticas públicas como a criação do ECA, a implantação do Conselho Tutelar e suas competências. É dever do Estado promover serviços públicos efetivos para que os sujeitos, isto é, crianças e adolescentes, tenham a oportunidade de gozar a infância e a juventude, usufruindo de direitos básicos como alimentação, moradia, saúde, lazer e educação.

Palavras-chave: Conselho Tutelar; Estatuto da Criança e Adolescente; Políticas Públicas.

\section{Guardianship Council: mechanism implemented by the ECA for the care of children and adolescents}

Social policies have been essential for minimizing social inequalities in Brazil. The Statute of the Child and Adolescent (ECA), through the Guardianship Counci, contributes significantly in favor of the child and the adolescent, improving the quality of life and its well-being. The present work has the objective of discussing the creation of the ECA, and about the actuation and competencies of the Guardianship Council before the regulatory guidelines. This is an exploratory bibliographic study. This bibliographic study demonstrated the opportunities generated for the benefit of the child through public policies such as the creation of the ECA, the implementation of the Guardianship Council and its competencies. It is the duty of the State to promote effective public services so that the subjects, that is, children and adolescents, have the opportunity to enjoy childhood and youth, enjoying basic rights such as food, housing, health, leisure and education.

Keywords: Guardianship Council; Statute of the Child and Adolescent; Public Policy.

\section{Topic: Serviço Social}

Reviewed anonymously in the process of blind peer.
Received: 10/01/2018

Approved: 13/03/2018
Reobbe Aguiar Pereira

Faculdade Guaraí, Brasil

http://lattes.cnpq.br/7447115724350334

reobbeap@hotmail.com

\section{Adriana Keila Dias}

Faculdade Guaraí, Brasil

http://lattes.cnpq.br/2128882976477548

adrianakeiladias@hotmail.com d

DOI: 10.6008/SPC2595-430X.2018.001.0001
Referencing this:

PEREIRA, R. A.; DIAS, A. K.. Conselho Tutelar: mecanismo implementado pelo ECA para o atendimento de crianças e adolescentes. Social Evolution, v.2, n.1, p.1-11, 2018. DOI: http://doi.org/10.6008/SPC2595-430X.2018.001.0001 


\section{INTRODUÇÃO}

Com os avanços nos direitos sociais da criança e do adolescente previstos pelo ECA, novos modelos de políticas sociais foram instituídos como a participação da sociedade civil, órgãos governamentais, movimentos sociais dentre outros em conselhos deliberativos e consultivos de formulação e implementação de políticas sociais. Um desses órgãos é o Conselho Tutelar, que visa assegurar os deveres e direitos de crianças e adolescentes.

Este artigo propõe analisar o avanço das políticas públicas voltadas às crianças e adolescentes após a promulgação do Estatuto da Criança e do Adolescente em 1990, com foco nas ações do Conselho Tutelar. Desta forma, os objetivos específicos foram relatar o processo histórico e desenvolvimento da gestão de Políticas Públicas que culminaram na promulgação do ECA no Brasil e analisar como o Conselho Tutelar tem assegurado o usufruto dos direitos da criança e do adolescente, conforme o ECA.

\section{MATERIAIS E MÉTODOS}

A metodologia deste artigo consistiu-se na revisão de literatura acerca do texto no qual está pautada a lei, que analisou o contexto histórico da gestão de Políticas Públicas no Brasil, após a promulgação do ECA, no que tange às ações do Conselho Tutelar. Trata-se de uma pesquisa aplicada de caráter qualitativo, descritivo e exploratório.

\section{DISCUSSÃO TEÓRICA}

\section{Sistema de Garantia de Direitos no Brasil}

A história dos direitos da criança e do adolescente no Brasil foi regida por inúmeras lutas sociais, mas também marcada pela predominância de costumes que retardaram a evolução dos direitos da criança e do adolescente no país. Houve dois marcos históricos no processo de evolução dos direitos da criança e do adolescente: o surgimento do Código de Menores, que pela primeira vez começou a tratar a criança e ao adolescente de forma diferenciada dos adultos; e a promulgação do ECA.

Com o Código, foi implantada uma Doutrina de Proteção do Menor em Situação Irregular. Tal Doutrina rompeu com o tratamento igualitário entre a criança e o adulto; já com o ECA, foi implantado a doutrina da proteção integral, que preconizava as crianças e adolescente como sujeito de direitos (LORENZI, 2007). O Código de Menores legislou no Brasil de 1927 a 1979, e versava que toda criança e jovem que vivesse em situações de abandono, carência, atos infracionais, deficiência física e que apresentava comportamento antissocial eram levados a instituições de recolhimento como a Fundação Estadual para o Bem Estar do Menor (FEBEM) e Fundação Nacional para o Bem Estar do Menor (FUNABEM). “[...] o Estado podia, através do Juiz de Menor, destituir determinados pais do pátio poder através da decretação de sentença de 'situação irregular do menor" (ARANTES, 1999). 
Quadro 01: O código de Menores de 1979 e o Estatuto da Criança e do Adolescente.

\begin{tabular}{|l|l|l|}
\hline $\begin{array}{l}\text { 1. Estatutos Legais } \\
\text { Médigo de }\end{array}$ & Código de Menores. & Estatuto da Criança e do Adolescente. \\
\hline 2. Doutrina Jurídica & Doutrina da situação irregular. & Doutrina da proteção integral. \\
\hline 3. Destinatários & $\begin{array}{l}\text { Menores entre zero e dezoito } \\
\text { anos que se encontra em situação } \\
\text { irregular (medidas de proteção). }\end{array}$ & $\begin{array}{l}\text { Todas as crianças e adolescentes (livro I); crianças e adolescentes } \\
\text { com direitos violados (livro II, título II, medidas de proteção) e } \\
\text { adolescentes suspeitos de ato infracional (livro II, título III, medidas } \\
\text { socioeducativas e de proteção). }\end{array}$ \\
\hline $\begin{array}{l}\text { 4. Concepção } \\
\text { política social } \\
\text { implícita }\end{array}$ & $\begin{array}{l}\text { Instrumento de controle social } \\
\text { dos menores carentes, } \\
\text { abandonados e infratores. }\end{array}$ & $\begin{array}{l}\text { Instrumento de desenvolvimento social para as crianças e } \\
\text { adolescentes e de proteção integral às crianças e adolescentes em } \\
\text { situação de risco. }\end{array}$ \\
\hline
\end{tabular}

Fonte: Frota (2003).

Tal doutrina foi substituída por um estatuto com amplos direitos para a criança e adolescente, que desta vez seriam vistos como sujeitos de direitos. A partir da Constituição Federal de 1988, outro marco no processo histórico que, devido às pressões de movimentos sociais, dedicou dois artigos para a questão da infância no Brasil, que mais tarde deram origem ao estatuto. Dos dois artigos da Constituição Federal, especificamente dos 227 e 229 derivou-se o Estatuto da Criança e Adolescente, no qual se instituiu um novo paradigma de atendimento da criança e adolescente, isto é, a Doutrina de Proteção Integral. A promulgação do ECA em 13 de julho de 1990 mudou substancialmente as diretrizes de atendimento e proteção à criança e adolescente (LORENZI, 2007).

Com os avanços nos direitos sociais da criança e do adolescente previstos pelo ECA, novos modelos de políticas sociais foram instituídos, como a participação da sociedade civil, órgãos governamentais, movimentos sociais dentre outros em conselhos deliberativos e consultivos de formulação e implementação de políticas sociais (COSTA, 1993). A Doutrina da Proteção Integral constituiu-se com as normativas da Organização das Nações Unidas no Brasil por meio do Estatuto da Criança e do Adolescente (ECA), na qual a criança e o adolescente são sujeitos de direitos assim como de deveres. No ECA, além de constar os direitos da criança e do adolescente, também se prevê os deveres assim como as punições de atos infracionais cometidos por sujeitos infanto-juvenis (LORENZI, 2007). Conforme Fachinetto (2003), a Doutrina de Proteção Integral possui três princípios básicos: (a) crianças e adolescentes como sujeitos de direitos; (b) Prioridade absoluta; e (c) condições de pessoas em desenvolvimento.

O princípio da criança e do adolescente como sujeitos ativos de direitos fundamentais previstos no art. 5 da Constituição Federal, sendo que todas as crianças e adolescentes são iguais perante a lei, tendo também deveres perante a sociedade (SARAIVA, 2003). O princípio da prioridade absoluta determina que é dever da família, sociedade e do Estado de dar prioridade aos direitos da criança e do adolescente, direitos estes referentes à vida, à educação, à alimentação, ao lazer e esporte, dignidade e respeito, assim como os demais direitos previstos nos direitos fundamentais da Constituição Federal (FACHINETTO, 2003).

O princípio de condições de pessoas em desenvolvimento está ligado ao princípio da prioridade absoluta, pois a criança e ao adolescente se encontram em processo de desenvolvimento físico, psíquico, moral e intelectual. Desta forma, as necessidades da criança e do adolescente não devem ser adiadas, pois contribuiriam negativamente para o desenvolvimento normal e integral da fase de crescimento da criança e adolescente para a idade adulta, podendo haver danos irreparáveis (SARAIVA, 2003). 
Em 2006, a Secretaria Especial dos Direitos Humanos e o Conselho Nacional dos Direitos da Criança e do Adolescente (CONANDA) assinaram a Resolução no 113, que institucionalizava e fortalecia o Sistema de Garantia dos Direitos da Criança e do Adolescente. Conforme a Resolução no 139, compete ao Sistema de Garantia de Direitos:

Art. 20 [...] promover, defender e controlar a efetivação dos direitos civis, políticos, econômicos, sociais, culturais, coletivos e difusos, em sua integralidade, em favor de todas as crianças e adolescentes, de modo que sejam reconhecidos e respeitados como sujeitos de direitos e pessoas em condição peculiar de desenvolvimento; colocando os a salvo de ameaças e violações a quaisquer de seus direitos, além de garantir a apuração e reparação dessas ameaças e violações. (BRASIL, 2010, p. 01).

A competência do Sistema de Garantia de Direitos (SGD) foi efetivada para enfrentar as desigualdades, explorações, discriminações e violência contra a criança e adolescente. As crianças e adolescentes, no decorrer da vida em sociedade, sempre sofreram discriminação e mazelas da sociedade, situação essa que se agrava, dependendo do nível social do sujeito.

Antes de a Constituição Federal de 1988, a criança e o adolescente não eram vistos como sujeitos de direitos, mas sim como sujeitos de exploração. O SGD veio para defender os direitos e deveres da criança e do adolescente (VIVARTA, 2005). O SGD integra e articula ações em defesa dos direitos da criança e do adolescente. $O$ sistema direciona e delimita diretrizes para a atuação dos órgãos que trabalhem em prol da defesa dos direitos da infância e juventude (BAPTISTA, 2012). Os atores das políticas de atendimento a criança e adolescente são: os Conselhos de Direitos; Conselho Tutelar; Entidades de Atendimento; Operadores do Direito e Sistema de Justiça; Agentes públicos; Instâncias representativas, a exemplo de fóruns e comitês; Formadores de opinião, trazendo-se como exemplo: Igrejas; Lideranças políticas; Comunicadores e artistas; e representantes da iniciativa privada, como: Empresários e organismos nacionais e internacionais.

A família, a comunidade, Programas de atendimentos aos direitos fundamentais de crianças e adolescentes e Políticas de assistência e proteção social também fazem parte dos interesses do Sistema de Garantia de Direitos (BRASIL, 2010). A estrutura do Sistema de Garantia de Direitos é regida pelos eixos de promoção, controle e defesa. A base do SGD é a política de atendimento, que conforme o art. 86 do ECA "a política de atendimento dos direitos da criança e do adolescente far-se-á através de um conjunto articulado de ações governamentais e não-governamentais, da União, dos Estados, do distrito Federal e dos Municípios" (VIVARTA, 2005). Isto é, para garantir a defesa dos direitos básicos da criança e do adolescente e promover políticas de assistência social, entidades civis e governamentais trabalham em conjunto para que a manutenção e garantia dos direitos sejam eficazes.

O eixo de promoção constituído pela sociedade, família e Estado, por meio das políticas públicas, realiza o atendimento direto a crianças e adolescentes fazendo valer seus direitos, na satisfação de necessidades básicas, medidas de proteção e socioeducativas (MOTTI et al., 1998). As entidades responsáveis são os Conselhos de Direitos, Conselhos Setoriais e Entidades de atendimento, seja na saúde, educação ou assistência social. Tais entidades formulam, deliberam e controlam políticas públicas sociais, políticas sociais básicas, políticas de seguridade social, políticas de atendimento e políticas de garantia dos direitos 
(BAPTISTA, 2012).

Fazem parte do eixo de controle ou vigilância os órgãos como Entidades de classe, Fóruns, os conselhos tutelares, Movimentos Sociais, ONGs, Sindicatos e a sociedade civil como um todo. No eixo de controle, ocorre parceria e aliança entre entidades governamentais e não-governamentais para que os direitos da criança e do adolescente sejam respeitados (BAPTISTA, 2012).

A responsabilização judicial pela violação dos direitos é acometida ao eixo de defesa, que atua quando os acordos feitos pelos Conselhos não são cumpridos. Dessa forma, os órgãos como Ministério Público, Defensoria Pública, Conselhos Tutelares e Centros de Defesa, Secretaria de Justiça e a de Segurança, por meio de medidas administrativas, político-sociais e judiciais tais órgãos visam o reestabelecimento de cumprimento de normas e diretrizes do ECA e do SGD garantindo o acesso à justiça e de recurso às instâncias públicas e jurídicas de proteção legal (BAPTISTA, 2012).

\section{Conselhos Tutelares}

A Constituição Federal de 1988 contemplou a participação popular como mecanismo de controle social, que por sua vez oportunizou a criação de Conselhos Tutelares em todo território brasileiro, que legitimaram a participação popular no processo de condução das Políticas Públicas de Atendimento da Criança e do Adolescente, que conforme o ECA, criança é até os 12 anos de idade incompletos, e adolescente até os 18 anos de idade incompletos (BRASIL, 1990).

O Conselho Tutelar teve seu início regulamentado a partir de 13 de julho de 1990 junto com Estatuto da Criança e do Adolescente (ECA), instituído pela Lei 8.069/90. No Brasil. Os Conselhos Tutelares são órgãos municipais destinados a zelar pelo cumprimento dos direitos da criança e do adolescente, conforme determinado no Estatuto da Criança e do Adolescente (BRASIL, 1990).

O Conselho Nacional de Direitos da Criança e do Adolescente (CONANDA) recomenda que, para cada 200 mil habitantes, deve haver, no mínimo, um Conselho Tutelar. Porém, fatores como extensão territorial e demandas sociais devem ser observados. As áreas onde são criados os Conselhos Tutelares são chamadas de microrregiões, e cada uma delas deve ser composta por cinco conselheiros tutelares, sendo que estes locais são determinados pela demanda social, isto é, a comunidade local pode atuar na criação de microrregiões justificando-se pela quantidade de denúncias e violações de direito de crianças e adolescentes local (ELIAS, 1994). Baseado na demanda social, Costa (2002) justifica a razão pela qual há a necessidade de haver mais de uma unidade do órgão ao dizer que:

Em cada comunidade deve haver, pelo menos, um Conselho Tutelar, porque cada local vive uma realidade de garantia ou violação de direitos, tem seus próprios problemas e deve organizar-se para resolve-los. Nesse sentido, o legislador, ao conceber o Conselho Tutelar, foi ao encontro do princípio municipalista da Constituição Federal e do apelo popular nacional pela descentralização de poder e democratização.

O caráter municipalista de cada localidade justifica a criação de mais Conselhos sempre que a comunidade julgar necessário devido às demandas sociais existentes e a maneira de organização do Conselho Tutelar, a fim de sanar as ameaças e violações de direitos da criança e do adolescente, já que cada localidade possui uma realidade distinta (ROSÁRIO, 2002). O Conselho Tutelar possui elementos característicos do 
órgão: uma vez constituído, não poderá ser extinto, sendo desta forma, um órgão permanente, e que mesmo com a mudança de gestores municipais, a continuidade da prestação do serviço é garantida (ROSÁRIO, 2002).

A autonomia do Conselho Tutelar concerne ao fato de que não é subordinado a nenhum outro órgão, pois mesmo sendo vinculado ao Poder Executivo Municipal, tem independência para tomar decisões, tendo sua atuação baseada somente no que prevê a legislação (ELIAS, 1994). O objetivo principal do órgão é encaminhar, zelar, fiscalizar e tomar as providências cabíveis quando uma criança ou adolescente que estiverem em situação de ameaça ou violação de seus direitos (BETIATE, 2007). O Conselho Tutelar é uma ferramenta da população para fiscalizar o atendimento a crianças e adolescentes, pois além de promover a garantia e defesa dos direitos, faz o acompanhamento para se certificar da continuidade de intervenção de suas ações sobre o indivíduo que teve seus direitos violados (ANDRADE, 2000).

\section{Competências do Conselho Tutelar}

O Conselho Tutelar é um órgão mobilizador e articulador que força mudanças sociais por meio de estruturas de Sistema de Garantia de Direitos no atendimento da criança e do adolescente, além de promover a responsabilidade dos que descumprem seus direitos mobilizando a sociedade e o Poder Público (MATOS et al., 2008).

As crianças e adolescentes têm seus direitos violados de inúmeras formas como a negligência familiar, abandono, violência sexual, psíquica, emocional, física, violência doméstica, trabalha infantil e quaisquer outras formas que agridam a dignidade moral e física (ANDRADE, 2000). Para Kamininski (2002), cabe à família e à sociedade a obrigação de proporcionar dignidade, saúde, educação e qualidade de vida a crianças e adolescentes, ou seja, não cabe a nenhum deles se eximir do cuidado e responsabilidade com crianças e adolescentes. Porém, quando isso não ocorre, o Conselho Tutelar além de prestar atendimento, ele cobra dos responsáveis os direitos que cabe à criança e ao adolescente, quando há a violação de seus direitos.

Dentre as principais competências do Conselho Tutelar estão atender, executar decisões por meio de requisições e notificações e assessorar o Poder Público. $O$ atendimento consiste na orientação, conselhos familiares e individuais e estímulos para que a criança, o adolescente e familiares estejam cientes dos direitos e deveres infanto-juvenis e assim respeitá-los, agindo de forma que evite novas violações (SIMÕES, 2009).

A requisição é uma forma oficial de uma autoridade administrativa, isto é, um pedido de uma autoridade pública, quem não a cumpre comete uma infração administrativa, conforme o art. 249 do ECA. $O$ Conselho Tutelar pode requisitar serviços de saúde, serviço social, educação, segurança, alimentação, habitação, lazer, segurança etc., sendo autorizado a requisitar serviços públicos para beneficiar e fazer valer os direitos da criança e do adolescente (SIMÕES, 2009).

A representação é outro instrumento do Conselho Tutelar, por meio dele o órgão através do conhecimento e comprovação de situação irregular pede as providências cabíveis ao Poder Judiciário. A notificação é um instrumento administrativo utilizado para informar uma medida ou decisão, sendo um instrumento de comunicação oficial entre o Conselho Tutelar e as pessoas envolvidas no atendimento 
(SOARES, 2002).

O Conselho Tutelar faz uso da notificação sempre que preciso para informar, marcar encontros, chamar atenção sobre comportamento e informar a decisão para o cumprimento de medidas. Além disso, o Conselho Tutelar tem o deve de notificar as autoridades competentes quando tem conhecimento de qualquer infração administrativa ou penal cometida por qualquer indivíduo (SIMÕES, 2009).

Como competência do Conselho Tutelar cabe ainda evitar situações de risco à criança e ao adolescente como proteger a criança e o adolescente quando frequentarem locais de esportes, cultura, lazer e diversões, proteger quanto às proibições ao uso de produtos e serviços como bebidas alcoólicas, entorpecentes, armas e explosivos, resguardar autorizações de viagem ao indivíduo titular do direito como crianças que não podem viajar sem autorização dos pais ou do responsável (ANDRADE, 2000).

\section{Ações do Conselho Tutelar}

No que cabe às ações de atendimento o Conselho Tutelar por meio do conselheiro tutelar realiza diligências, visitas domiciliares, ouve interessados, realiza estudos e pesquisas para assessorar o Poder Público, aplica medidas protetivas e medidas socioeducativas (SIMÕES, 2009). Segundo o ECA, as medidas de proteção são aplicadas quando os direitos da criança e do adolescente são ameaçados ou violados, em casos de conduta inadequada, falta, abuso ou omissão dos pais e responsáveis e por ação ou omissão da sociedade ou do Estado. Propõe-se: o encaminhamento aos pais ou responsável; a orientação, apoio e acompanhamento temporários; a matrícula e frequência obrigatórias em estabelecimento de ensino fundamental; a inclusão em programa comunitário ou oficial de auxílio à família, à criança ou adolescente; a requisição de tratamento médico, psicológico ou psiquiátrico, em regime hospitalar ou ambulatorial; a inclusão em programa oficial ou comunitário de auxílio, orientação e tratamento a alcoólatras e toxicômanos; e o abrigo em entidade.

O Conselho Tutelar tem competência para aplicar sete medidas de proteção à criança e ao adolescente como o encaminhamento ao pai e responsável, requisição de tratamento médico, psicológico ou psiquiátrico, matrícula e frequência obrigatórias em instituição de ensino, inclusão em programas comunitários de auxílio à família, à criança e ao adolescente, inclusão em programas de auxílio e tratamento de toxicômanos e alcoólatras e abrigo em entidade (BRASIL, 1990).

Já as medidas aplicadas aos pais e responsáveis consistem em encaminhar a programa comunitário oficial, encaminhamento psicológico e psiquiátrico, inclusão em programa oficial comunitário para alcoólatras e toxicômanos, advertência, perda de guarda, destituição de tutela, obrigação de acompanhar a criança ou adolescente em tratamento especializado e suspensão ou destituição do poder familiar (SOARES, 2002). Nos casos de ato infracional cometidos por crianças, o Conselho Tutelar aplica as medidas de proteção, porém nos casos de adolescentes são aplicadas medidas socioeducativas, nas quais algumas são cabíveis a atuação em conjunto com o Poder Judiciário, já que o Conselho Tutelar não possuem competência jurisdicional (SIMÕES, 2009).

O art. 112 do ECA prevê as medidas socioeducativas como a advertência, obrigação de reparar o 
dano, prestação de serviços à comunidade, internação em estabelecimento educacional, em caso de adolescentes infratores, liberdade assistida e prestação de serviço à comunidade. Tais ações representam o acompanhamento da criança e adolescente pelo Conselho Tutelar e o Poder Judiciário com a finalidade de serem reestabelecida a dignidade e as atividades normais para o desenvolvimento psíquico e emocional deles (SOARES, 2002). No que concerne ao auxílio ao Poder Executivo, o Conselho Tutelar pode prestar assessoria para a criação e implementação de Políticas Públicas através da participação social dos Conselhos, pois baseado nas demandas existentes nos municípios os conselheiros tutelares podem apontar as necessidades existentes na comunidade no que diz respeito a melhorar a qualidade de vida da criança e adolescente e promover a defesa dos seus direitos (FERREIRA, 2000).

O Conselho Tutelar deve ainda trabalhar articulado com as rede do Sistema de Garantia de Direitos, desta forma será possível o efetivo atendimento às demandas sociais relativas à criança e ao adolescente. A articulação das autoridades competentes mobiliza recursos, demandas e disponibiliza políticas públicas em prol da criança e do adolescente (MATOS et al., 2008).

\section{Política de atendimento à criança e ao adolescente: diretrizes ideais}

Existem inúmeras diretrizes para o funcionamento dos Conselhos Tutelares, o presente trabalho abordará sobre a importância da capacitação contínua de conselheiros tutelares, sobre a infraestrutura da instituição e sobre os recursos humanos. O CONANDA tem o poder de formular diretrizes gerais para o atendimento dos diretos das crianças e dos adolescentes, bem como avaliar as políticas aplicadas no âmbito dos estados e municípios e a atuação dos conselhos de tutelares (SALES, 2004). O seu conceito já diz muito, visto que a palavra diretriz significa caminho, direção, sentido, entre outros. Poderão ser traçadas pelos próprios conselhos tutelares ou outros órgãos da rede de proteção, respeitados os limites legais de atribuição de cada um (VIVARTA, 2005).

Contudo, na prática, as diretrizes não são obedecidas em sua totalidade. Os Conselhos Tutelares, para funcionarem de modo eficaz, deverão contar com uma estrutura física apropriada e materiais necessários para os atendimentos, tais como de expediente, permanentes, veículos, entre outros (NASCIMENTO et al, 2010). Mesmo decorridos mais de vinte anos após aprovação do ECA, os Conselhos Tutelares ainda se deparam com problemas estruturais, logístico, humanos e financeiros. Conforme Lemos (2011), ao exemplificar a situação dos conselhos tutelares de determinado Município, ratifica que

As condições de atuação dos conselheiros tutelares eram de certo modo difíceis, com várias situações complicadas, tais como espaço físico limitado; ausência de veículo próprio para realizar as visitas necessárias; pressões políticas de grupos patrimonialistas e corporativistas; ausência de projetos de defesa e garantia dos direitos de crianças e dos adolescentes [...]. Constantemente, os conselheiros tinham que emprestar os carros de outros órgãos; não tinham equipamentos de informática; a organização do espaço não permitia acolher a comunidade; a sede foi transferia para vários locais, em pouco tempo.

Essa realidade ainda se faz presente em muitos municípios. Destaca-se, também, que a falta de treinamento dos conselheiros, a insuficiência de materiais, e a estrutura deficiente da sede dos Conselhos poderão prejudicar o atendimento prestado às crianças e adolescentes, no sentido de defender os seus direitos (NASCIMENTO et al., 2010). Todos os expedientes necessários para a instalação, manutenção e 
funcionamento do órgão deve estar previsto na Lei Orçamentária Municipal, sendo consideradas as particularidades de cada município (BRAGAGLIA, 2005).

Sobre a infraestrutura, a preferência é que o prédio seja localizado em local de fácil acesso e conhecido pela população, é orientado ainda que a localização do Conselho Tutelar seja em local fixo, isto é, que a localização não mude, por exemplo, na mudança de um governo para outro, pois prejudica o conhecimento das pessoas sobre a localização do órgão (NASCIMENTO et al., 2010).

Outro fator apontado por Matos et al. (2008), que concerne à atuação do Conselho Tutelar, referese à dificuldade de desempenhar adequadamente o papel de fiscalizar as instituições de atendimento junto a outros órgãos como o Ministério Público e Defensoria Pública, havendo a falta de interação entre os Conselhos de Direitos. A ausência de infraestrutura, profissionais, materiais de expedientes etc. em uma instituição, pode prejudicar a interação de todos os demais.

O Sistema de Informações Para a Infância e Adolescência (SIPIA) é responsável por operacionalizar o trabalho dos conselheiros tutelares em um sistema nacional de registros com informações sobre os atendimentos diários. Com a utilização deste sistema pode ser observadas as providências tomadas para cada atendimento e ainda ter conhecimento sobre as demandas existentes em cada município, auxiliando desta forma, a criação de políticas públicas voltadas para cada necessidade isolada (VIVARTA, 2005). O SIPIA está subdividido em módulos que contemplam, segundo Matos et al (2008): casos de violação de direitos; dados sobre medidas socioeducativas aplicadas e em quais instituições; informações sobre adoção; e registro de Conselhos Tutelares em todo o país com endereço e telefone.

Porém, com a precariedade de infraestrutura, equipamentos eletrônicos como impressora, computadores com internet e telefones, mesmo com a existência de mecanismos eficazes o trabalho do Conselho Tutelar não tem eficácia. Até mesmo o SIPIA, feito para ser usado nacionalmente, não é uma realidade para todos os municípios do país (VIVARTA, 2005). "A sua instalação depende da existência de uma infraestrutura que a maioria dos Conselhos Tutelares não dispõe. A implantação do SIPIA pressupõe, no mínimo, a existência de computadores, linhas telefônicas e pessoal capacitado" (MATOS et al., 2008).

Outra dificuldade encontrada apontada por Vivarta (2005) é a falta de capacitação contínua para os conselheiros tutelares, uma vez que precisam alimentar o banco de dados do SIPIA ainda precisam tomar providências corretas e adequadas para cada caso. Veloso (2010) enfatizou que as mudanças tecnológicas aumentam as condições de potencializar os resultados positivos no Conselho Tutelar, pois além de ser um meio de divulgar informações também é útil para obtê-las.

Contudo, existem municípios em que a atuação do Conselho Tutelar é eficaz, seguindo as diretrizes do ECA, como o prefeito da cidade de Goiânia, que ficou conhecido como Prefeito Amigo da Criança, devido ao bom funcionamento dos quatro Conselhos Tutelares na cidade que possui ótimas condições de infraestrutura, carro, motorista, aparelhos eletrônicos, os profissionais possuíam remuneração de $\mathrm{R} \$ 1,5 \mathrm{mil}$, com carga horária de 08h às 18 h (VIVARTA, 2005).

Isso demonstra que é preciso haver um trabalho conjunto entre o Poder Público Municipal e as instituições que zelam pela defesa dos direitos da criança e do adolescente. Enfim, a prestação do serviço à 
população realizado pelo Conselho Tutelar depende das condições estruturais dadas aos profissionais para que eles potencializem ou limitem a atuação na defesa dos direitos da criança e do adolescente.

\section{CONSIDERAÇÕES FINAIS}

Atualmente, as políticas públicas têm buscado atender às necessidades de crianças e adolescentes. O Conselho Tutelar é um mecanismo institucional que auxilia na busca de direitos, melhorar a qualidade de vida e proporcionar bem-estar às crianças e adolescentes, garantindo a elas a defesa dos direitos básicos da criança e do adolescente e promover políticas de assistência social, entidades civis e governamentais trabalham em conjunto para que a manutenção e garantia dos direitos sejam eficazes. No entanto, deve haver o entendimento de que é preciso que a teoria atenda a prática. Desta forma, as políticas públicas devem ser feitas com base em necessidades específicas das crianças e adolescentes.

Este estudo bibliográfico demonstrou as oportunidades geradas em prol da criança e do adolescente por meio das políticas públicas como a criação do ECA, a implantação do Conselho Tutelar e suas competências. É dever do Estado promover serviços públicos efetivos para que os sujeitos, crianças e adolescentes, tenham oportunidade de gozar a infância e a juventude usufruindo de direitos básicos como alimentação, moradia, saúde, lazer e educação.

\section{REFERÊNCIAS}

ANDRADE, J. E.. Conselhos tutelares: sem ou cem caminhos?. São Paulo: Veras, 2000.

ARANTES, E. M.. De "criança infeliz" a "menor irregular": vicissitudes na arte de governar a infância. Rio de Janeiro: NAPE, 1999.

BAPTISTA, M. V.. Algumas reflexões sobre o sistema de garantia de direitos. Revista Serviço Social e Sociedade, n.109, São Paulo, 2012.

BETIATE, L.. Direitos Sociais do Conselho Tutelar. Ibiporã: Novagraf, 2007.

BRAGAGLIA, M.. Conselho Tutelar: gênese, dinâmica e tendências. Canoas: Ulbra, 2002.

BRASIL. Constituição da República Federativa do Brasil de 1988. Brasília: 1990.

BRASIL. Estatuto da Criança e do Adolescente. Brasília, 1990.

BRASIL. Resolução n.139.Brasília: 2010.

BRASIL. Resolução n.466. Brasília: 2012.

COSTA, A. C. G.. De menor a cidadão: notas para uma história do novo direito da infância e juventude no Brasil. Brasília: Senado Federal, 1993.
COSTA, A. P. M.. Elementos que favoreceram e incidiram sobre a criação do Conselho Tutelar. Canoas, 2002.

ELIAS, R. J.. Comentários ao Estatuto da Criança e do Adolescente. São Paulo: Saraiva, 1994.

FACHINETTO, N. J.. Evolução Doutrinária dos Direitos da Criança e do Adolescente. Santa Cruz do Sul: 2003.

FERREIRA. K. M. M.. Perspectivas do Conselho Tutelar para o século XXI. Canoas: ULBRA, 2002.

FROTA, M. G. C.. A cidadania da infância e da adolescência. Belo Horizonte: UFMG, 2003.

KAMININSKI, A. K.. Conselhos tutelares: perspectivas. In: Conselho Tutelar: Gênese Dinâmica e Tendências. Canoas: 2002.

LEMOS, F. C. S.. Conselhos Tutelares: desafios teóricos e práticos da garantia de direitos da criança e do adolescente. Belo Horizonte: UFJF, 2011.

LORENZI, G.. Uma breve história dos direitos da criança e do adolescente no Brasil. São Paulo: 2007.

MATOS, M. C.; MENDES, A. G.. Uma agenda para os conselhos tutelares. In: Política social, família e juventude: uma questão de direitos. São Paulo: Cortez, 2008. 
MOTTI, A. J. A.; SEDA, E.. A Criança e seu Estatuto no Brasil. Campinas: Adês, 1998.

NASCIMENTO, A. F.. Teoria e Prática dos Conselhos Tutelares e Conselhos dos Direitos da Criança e do Adolescente. Brasília: Fiocruz, 2010.

ROSÁRIO, M.. O Conselho Tutelar como órgão de defesa de direitos num cenário de exclusão social. Canoas, 2002

SARAIVA, J. B. C.. Adolescente em conflito com a lei: da indiferença à proteção integral. Porto Alegre: Livraria do Advogado, 2003.

SIMÕES, C.. Curso de direito do Serviço Social. São Paulo: Cortez, 2009.

SOARES, J. J. B.. Estatuto da Criança e do Adolescente Comentado. 5 ed. São Paulo: Malheiros, 2002.

VIVARTA, V. Ouvindo conselhos: democracia participativa e direitos da infância na pauta das redações brasileiras. São Paulo: Cortez, 2005.

A CBPC - Companhia Brasileira de Produção Científica (CNPJ: 11.221.422/0001-03) detém os direitos materiais desta publicação. Os direitos referem-se à publicação do trabalho em qualquer parte do mundo, incluindo os direitos às renovações, expansões e disseminações da contribuição, bem como outros direitos subsidiários. Todos os trabalhos publicados eletronicamente poderão posteriormente ser publicados em coletâneas impressas sob coordenação da Sustenere Publishing, da Companhia Brasileira de Produção Científica e seus parceiros autorizados. Os (as) autores (as) preservam os direitos autorais, mas não têm permissão para a publicação da contribuição em outro meio, impresso ou digital, em português ou em tradução. 